\title{
AVALIAÇÃO FORMATIVA: A AUTO-AVALIAÇÃO DO ALUNO E A AUTOFORMAÇÃO DE PROFESSORES
}

\section{Formative Assessment: students self-assessment and teachers self-education}

\author{
Lizete Maria Orquiza de Carvalho ${ }^{1}$ \\ Carmem Lidia Pires Martinez ${ }^{2}$
}

\begin{abstract}
Resumo: Este artigo é parte de uma dissertação de mestrado na qual analisamos a reflexão sobre a prática de avaliação realizada por professores de Ciências de uma escola estadual de educação básica, durante os horários de trabalho pedagógico coletivo (HTPC). Acompanhamos, durante seis meses, a perspectiva de implementação da avaliação formativa por estes professores, o que se deu a partir do estudo de um texto básico, bem como analisamos as repercussões do estudo feito pelo grupo na autoformação dos professores e na reflexão dos pesquisadores envolvidos na investigação-ação.
\end{abstract}

Unitermos: avaliação formativa, educação de professores, Educação em Ciências.

Abstract: This paper is part of a masters' degree dissertation in which we analyze Science teachers' reflections on assessment practice that took place in a public basic school, during collective pedagogical work hours. We followed, during six months, the teachers' perspective of putting formative assessment into practice by having a formative assessment text as a starting point. We also analyzed the repercussions of reflections on teachers' self-education and on investigation-action researchers' thinking.

Keywords: formative assessment, teacher education, Science Teaching.

\section{Introdução}

Até pouco tempo, as pesquisas sobre formação de professores eram predominantemente normativas (Orton, 1997), o que significa que se preocupavam em definir como deveria ser o trabalho do professor, quais os tipos de raciocínio e qual o corpo de conhecimentos a serem dele exigidos. Shulman (1987), por exemplo, não somente descreveu o professor como um profissional que emprega um corpo de conhecimentos (base knowledge) e uma série de estratégias racionais para exercer seu trabalho, como buscou caracterizar este corpo de conhecimentos, incluindo nele o conteúdo específico, o conteúdo pedagógico, conhecimento pedagógico do conteúdo e o currículo.

Na década de 1990, a atenção dos pesquisadores voltou-se para compreender a prática profissional dos professores, através dos saberes efetivamente utilizados por eles, no seu trabalho cotidiano. Inspirado em Aristóteles, Orton (1997) propôs que o raciocínio do professor, além de prático e teórico, por refletir sobre o conteúdo específico e sobre o seu trabalho, seria também produtivo, pois o professor cria elementos para a aprendizagem dos alunos. Seus argumentos evidenciaram que o raciocínio e as ações do professor eram também influenciados por componentes não racionais.

A análise de Tardif (2000) alargou a noção de corpo de conhecimento no sentido de incluir um ponto de vista fenomenológico. Para ele, a definição do corpo de conhecimento seria baseada "no estudo dos saberes profissionais dos professores tais como estes os utilizam e

\footnotetext{
${ }^{1}$ Professora Assistente Doutora do Departamento de Física e Química da Faculdade de Engenharia da Universidade Estadual Paulista (Campus de Ilha Solteira). E-mail: lizete@dfq.feis.unesp.br

${ }^{2}$ Doutoranda do Programa de Pós-graduação em Educação para a Ciência da Universidade Estadual Paulista (Campus de Bauru).E-mail: carmemilidia@hotmail.com
} 
mobilizam nos diversos contextos do seu trabalho cotidiano" (Tardif, 2000, p. 20). Para este autor, a integração que o professor faz sobre os seus saberes não se relaciona à busca de coerência lógica entre eles, mas à busca de coesão com a sua prática de trabalho. Esta integração manter-se-ia em função de vários objetivos coexistentes, tais como procurar controlar a classe, motivar os alunos, dar explicaçôes, cobrir o conteúdo e sobreviver profissionalmente, que inclusive são de naturezas diferentes (emocional, ética, pessoal etc.).

Para os professores da escola, os saberes acadêmicos sobre a sala de aula irão sempre conter certo grau de estranheza, pelo fato de eles serem "organizados em categorias gerais e abstratas e idealizarem, fragmentarem e simplificarem a prática concreta e complexa da sala de aula" (Fiorentini, 2001, p. 310). Fiorentini defende que a questão mais difícil é rever a crença, comum na escola, de que o saber oriundo da produção científica é inquestionável e diretamente aplicável à prática. Lembrando o alerta, feito por Maturana e Varela (2001), sobre o perigo da assunção da metáfora do tubo, segundo a qual "a comunicação é algo que se produz em um ponto, é levada por um conduto, e entregue no outro extremo" (p. 218), ressaltamos que a própria decodificação dos saberes acadêmicos, pelos professores da escola, implica a construção de um quadro teórico-metodológico próprio, que lhes permite não somente compreender o ponto de vista acadêmico, mas lidar com a complexidade de sua realidade na escola.

Diante dessa exigência, no entanto, deparamo-nos com um impasse, uma vez que, se por um lado, é clara a necessidade de que o professor reinterprete as teorias dos especialistas, produzindo uma teoria e uma ação diferentes, que podem passar pela própria negação da teoria dos especialistas; por outro, ele somente consegue fazê-lo se já estiver de posse de um quadro teórico-epistemológico mínimo que lhe possibilite o acesso àquelas teorias. Sabemos, no entanto, que a maioria dos professores permanece à margem da cultura de exposição do professor a teorias educacionais. Para Huberman (apud Sawyer, 2001), os professores estariam mais interessados em trocar informaçôes sobre atividades e comportamentos dos estudantes do que sobre teorias e estratégias pedagógicas. Esta dificuldade se deveria à necessidade de manutenção do respeito profissional aos pares, à tolerância para com as preferências e aos estilos individuais, e ao desejo de evitar a arrogância. Ainda, segundo Tardif (2001), os saberes dos professores são "pessoais, tácitos e íntimos", de tal forma que é difícil, para eles, teorizarem sobre sua prática e formalizar seus saberes.

\section{O Quadro Teórico levado para o grupo: Avaliação Formativa}

\section{A dimensão legal da avaliação no cotidiano das escolas públicas estaduais em São Paulo}

O regime de progressão continuada, instituído no Sistema Estadual de Ensino em São Paulo, pela Deliberação do Conselho Estadual de Educação - CEE no 09/97, impôs a necessidade de um novo tratamento para o processo de avaliação realizado na escola, no sentido de modificar as práticas de avaliação, que são predominantemente classificatórias e somativas, tornando-as mais formativas e interativas. Os professores da escola pública foram surpreendidos pelas mudanças através de múltiplas interpretações das informações veiculadas pela Secretaria Estadual de Educação. O sentimento geral de quem vive o dia-a-dia escolar é o de que a grande maioria dos professores perdeu suas referências sobre avaliação: alguns utilizam a avaliação como instrumento de controle disciplinar, muitos entendem que não precisam mais aplicar avaliaçôes e outros tentam inovar realizando provas em grupo ou com consultas realizadas em livros didáticos ou no caderno do aluno; poucos ainda ignoram as mudanças e continuam com seus hábitos tradicionais de avaliaçãa. Desta forma, do ponto de vista das pesquisadoras, há a necessidade de aprofundamento das bases teóricas do novo paradigma sobre avaliação. 
A proposta da Deliberação do CEE, com fundamento na Lei Federal no 9.394, é ampliar o conceito de avaliação, de modo que este seja entendido também como um instrumento-guia essencial para a observação contínua da progressão do aluno subsidiando o aperfeiçoamento do ensino praticado. O processo deve sinalizar as heterogeneidades do desenvolvimento de habilidades e conhecimentos entre os alunos, servindo como orientação para a própria aprendizagem dos alunos e para o ensino do professor. Entendida dessa maneira, a avaliação é comumente identificada como "formativa".

\section{Avaliação Formativa e Auto-Avaliação}

$\mathrm{Na}$ literatura, a noção de avaliação formativa foi introduzida por Scriven, em 1967, em oposição à avaliação "somativa" (Abrecht, 1994, p. 33). O termo "avaliação somativa” refere-se à avaliação que pretende, ao final de um período, dar uma visão geral sobre o desempenho do estudante (Black \& Wiliam, 1998a). Abrecht (1994) traça a diferença entre este tipo de avaliação e a avaliação formativa através da definição do papel do erro em cada uma delas. Enquanto a verificação dos conhecimentos adquiridos ao final de um período (avaliação somativa) implica na consideração do erro como uma "falta" definitiva de algo (uma vez que não se pretende voltar mais a ele), no enfoque da avaliação formativa, essa falta é apenas momentânea. A falta apontada pelo erro é, então, considerada como parte integrante do processo de aprendizagem.

Para Piaget (1993), a abertura de novas possibilidades a serem consideradas pelo aprendiz, não se dá por livre associação de idéias, mas através da "liberação de limitações resistentes". O erro assim viria "denunciar" estas limitações, possibilitando a apropriação de novos aspectos de um novo referencial a ser compartilhado na sala de aula.

O conceito de regulação é um importante ponto de partida para descrever o processo de interação social envolvido nos processos de avaliação. Segundo Perrenoud (1999), regulação é o conjunto das operaçôes metacognitivas do aprendiz e de suas interações com o meio que modificam seus processos de aprendizagem no sentido de um objetivo definido de dominio.

$\mathrm{Na}$ interação com o meio, o aprendiz recebe "informações sobre o seu desempenho numa ação" (Black e Wiliam, 1998a), podendo ter diferentes reaçôes para a sua percepção do desnivelamento ( $g a p$ ) entre dois níveis de referência, aquele que ele atribui à mensagem recebida e aquele que ele associa ao estado presente. Diante da mensagem recebida o aprendiz poderia se perguntar: "há diferença entre os dois níveis?"; ou "qual é a aproximação entre eles?"; ou ainda "o que eu devo fazer para chegar lá?”. Sadler (1989, apud Black \& Wiliam, 1998a) propõe que a função formativa seja atribuída ao feedback somente no último caso. A mensagem que está por trás da validação desta terceira resposta como sendo a única de caráter formativo estabelece a valorização da auto-regulação do processo de aprendizagem ou auto-avaliação.

Sobre a auto-regulação (auto-avaliação), Perrenoud (1999) afirma que "não se trata mais de multiplicar os feedbacks externos, mas de formar o aluno para a regulação de seus próprios processos de pensamento e aprendizagem". Segundo Sadler (1989, apud Black \& Wiliam, 1998a), a ação do aprendiz poderá ser inibida se o desnivelamento for visto como largo demais. Assim, o processo da avaliação formativa consiste em caminhar por sucessivas aproximações e por constantes redefinições de metas.

\section{Os contornos da pesquisa}

Construímos nosso cenário de pesquisa supondo que um grupo de professores que realiza um projeto comum, no recinto da escola, pode conter os elementos necessários para a 
constituição de um ambiente favorável à atividade coletiva dos professores. Perguntamo-nos: em quais condições um grupo de professores pode representar o espaço de formação teóricoepistemológica, que seja ao mesmo tempo instância de validação do quadro teórico/prático dos mesmos?

No interior desse cotidiano escolar e de sala de aula, fizemos um recorte destacando a avaliação dentro de um processo de prática docente e discente.

\section{Descrição do Projeto}

A pesquisa foi realizada com 5 professores de uma escola pública do interior do Estado de São Paulo que constituíam um grupo específico atuando na área de Ciências e de Biologia, imerso em uma atividade coletiva de estudo sobre determinado quadro teórico, a avaliação formativa. Os encontros ocorreram durante os Horários de Trabalho Pedagógico Coletivos (HTPC), reuniōes pedagógicas e encontros informais nos intervalos das aulas.

Os professores do grupo, codificados como P1, P2, P3, P4 e P5, atuavam no ensino público estadual há, respectivamente, 30, 25, 20, 10 e 7 anos. Enquanto os professores P1, P2, P3 e P4 eram efetivos, a professora P5 era a única admitida em caráter temporário (ACT). Após ter atuado como professor primário, professor de Matemática no antigo ginásio, coordenador de área na Escola Padrão e vivido dois anos como aposentado, P1 voltou à ativa, através de concurso público, como professor de Ciências. P2 atuava como professor de Ciências e Química. P3, que exerceu função como coordenadora pedagógica por dois anos, atuava ora como professora de Ciências e Biologia, ora no cargo de Vice-Diretora substituta. P4 ocupava função de coordenadora pedagógica, no período diurno, e professora de Biologia, no período noturno. Por fim, P5 atuava como professora de Ciências e Biologia.

A proposta, que consistia no estudo sistemático de textos e na reflexão sobre a prática dos professores, foi apresentada ao grupo por um de seus componentes, P3 (CLPM), no primeiro de uma série de 16 encontros ocorridos num semestre. A compreensão da realidade do trabalho docente por P3, que na época cursava mestrado em Educação para a Ciência, levou-a ao delineamento de possíveis intervenções junto ao grupo.

As atividades desenvolvidas pelo grupo foram: leitura e discussão de texto da literatura sobre avaliação formativa; leitura e discussão da Deliberação Estadual CEE no 9/97, que instituiu a progressão continuada no Estado de São Paulo; busca, motivada pelo estudo dos textos, de um caso real e exemplar, em outra escola da rede pública, que foi discutido no grupo; proposta e elaboração de uma ficha de registro das atividades de avaliação a serem desenvolvidas com os alunos, com base na prática do exemplo estudado.

O texto da literatura discutido foi escrito por Paul Black e Dylan Wiliam (1998b), e intitula-se Inside the Black Box: Raising Standars Through Classroom Assessment. Ele foi levado ao grupo através de uma versão em português, realizada por nós.

O objetivo básico deste texto é definir algumas direções para os esforços de aprimoramento da avaliação em sala de aula, a serem realizados pelo professor. A primeira consiste em dar especial atenção aos alunos presos à armadilha do baixo rendimento, o que seria feito através de mensagens que endereçassem exclusivamente aspectos inerentes à atividade desenvolvida. A segunda consiste em incentivar a auto-avaliação, encorajando o aluno a buscar metas estabelecidas e assumidas por ele mesmo. A terceira consiste em fundir ensino com avaliação, o que implica conceber a avaliação como um veículo para o diálogo permanente na sala de aula. Em conjunto, as três direçôes levam o professor a privilegiar o processo de produção intelectual dos alunos através da criação de oportunidades para que eles exponham seu pensamento e apliquem os feedbacks recebidos em situações posteriores. Ao final do texto são sugeridos 
direcionamentos para uma política de implementação da avaliação formativa nas escolas: partir do compromisso de pequenos grupos de professores; encorajar os professores a buscar seu modo próprio de incorporar os resultados das pesquisas à prática de sala de aula; contar com o apoio de formadores "que sabem o que fazer"; buscar exemplos reais e vívidos de implementação; e incentivar os professores ao exame de características do sistema educacional que obstruem a prática da avaliação formativa.

Os dados analisados constituíram-se basicamente de transcrições das gravações dos 10 primeiros encontros, nos quais os dois textos referidos foram discutidos. Embora, neste trabalho, discorramos apenas sobre a análise de alguns episódios, ressaltamos que as nossas categorias de análise foram criadas a partir de inúmeras idas e vindas entre a literatura e o conjunto de dados que correspondem a estes 10 encontros (Martinez, 2001).

\section{Ampliando o foco: a autoformação do professor}

Apesar de o objeto dos estudos do grupo ter sido, desde o começo, a avaliação formativa, um efeito produzido pela atividade realizada consistiu no alargamento do foco do estudo para incluir reflexões sobre a autoformação do professor. Isto ocorreu, em parte, devido às preocupações das pesquisadoras, que se ocupavam com os dois campos de pesquisa e, em parte, porque a melhoria da avaliação formativa necessita que sua atenção não contemple apenas o aluno, individualmente, mas o processo interpessoal de ensino e aprendizagem em que ele está envolvido. Sendo assim, pensar e tentar implementar a avaliação formativa na escola implica olhar, sobretudo, para o professor, e não apenas para o aluno, pois é o professor quem tem que sustentar o processo de implementação das idéias vindas da leitura dos textos teóricos sobre avaliação formativa.

Do ponto de vista do professor a avaliação formativa supõe, em primeiro lugar, a crença sobre a possibilidade de que pequenas mudanças sejam paulatina e incansavelmente introduzidas na prática de sala de aula, a partir de análises que o professor faz da situação por ele vivida com seus alunos, em cada momento. Em segundo lugar, supõe investimento, por parte do professor, na promoção contínua do envolvimento do aluno com sua auto-avaliação, entendida como desenvolvimento da expectativa do aluno de produzir análises próprias da situação que está vivenciando e disparar pequenas ações no sentido de lidar com ela.

O alargamento do foco de estudo do grupo ocorreu dentro de um processo que acarretou, também, redefinição dos objetivos de pesquisa. Estes terminaram por abranger a relação entre o tema estudado e suas repercussões na reflexão sobre autoformação do grupo.

As perguntas que nos fazíamos então eram: como os professores, em especial, os da escola pública, estão lidando com o paradigma “imposto" pela legislação mencionada anteriormente? Eles estão discutindo o referencial teórico implícito nos textos sobre o processo de ensino e aprendizagem e respectiva avaliação, colocados pela legislação e pelos administradores? Eles estão reconhecendo alguma lacuna entre os padrões de referência implícitos nesse referencial e a realidade que enfrentam em suas salas de aula? Pesquisar sobre a avaliação do aluno realizada pelos professores implica observar estes últimos em situações em que estão refletindo sobre suas práticas docentes e avaliativas? É possível oferecer oportunidades para que o aluno se auto-avalie, se o próprio professor não lida bem com auto-avaliação do processo no qual ele tem importante papel como mediador?

\section{Análise dos Dados}

A ressonância entre as preocupações com a avaliação formativa e com a formação de professores afetou também a análise dos nossos dados, de tal modo que indagamos se era 
possível pensar um processo, vivido pelo professor, semelhante àquele vivido pelo aluno. A contraposição dos nossos dados referentes às falas dos professores nos encontros com estes referenciais teóricos levou-nos a identificar relações entre as pesquisas sobre avaliação formativa e sobre conflitos cognitivos (Villani e Orquiza de Carvalho, 1995).

\section{Lacuna, Desnivelamento, Padräo de Referência e Estabelecimento de Metas}

A certa altura do processo de análise sentimos necessidade de diferenciar os conceitos de lacuna e desnivelamento, duas possíveis traduçōes do termo gap, palavra da língua inglesa utilizada pelo autor do texto levado aos professores. A palavra lacuna remeteu-nos ao conceito de conflito cognitivo (Villani e Orquiza de Carvalho, 1995): uma insatisfação gerada quando o aprendiz depara-se com um conhecimento que gostaria de ter e, portanto, sente falta; o que caracteriza uma lacuna a ser preenchida.

É importante salientar que, no trabalho de Villani e Orquiza de Carvalho, o termo lacuna é utilizado ora referindo-se aos conflitos potenciais (aqueles percebidos somente pelo professor ou pelo pesquisador) e ora aos conflitos efetivos (aqueles efetivamente percebidos pelo aprendiz).

Diferentemente, no atual trabalho, entendemos por lacuna a simples diferenciação entre dois pontos de vista, sem nos importarmos em definir quem é o sujeito que está percebendo esta lacuna, se é o pesquisador ou o aprendiz da pesquisa, se é o professor ou o aluno. Este entendimento parece estar de acordo com o emprego que Villani (1999) fez desta palavra, no seguinte trecho: Há duas estratégias diferentes de problematizar um conteúdo: tornar explícita a presença de lacunas, num campo de conhecimento no qual o aluno quer ser minimamente competente, ou provocar conflitos, em situaçôes que o aluno quer resolver (p. 280). Nesta frase, a lacuna é percebida somente pelo professor, uma vez que é sua tarefa "torná-la explícita".

Por desnivelamento, entendemos que o sujeito percebeu a lacuna e reconheceu a relevância da referência nela implícita. A novidade no nosso trabalho é o reconhecimento de que somente a valorização da lacuna, pelo aprendiz, é que torna possível falarmos em algo que tenha o status de padrão de referência, em oposição ao estado presente (ou realidade percebida por ele) e, portanto, em auto-avaliação.

Segundo Kluger e DiNisi (1996), a comparação entre o padrão de referência e o estado presente pode ser feita em termos de igualdade, quando o aprendiz pergunta-se se o padrão de referência e o estado presente "são os mesmos ou são diferentes", distância, quando o aprendiz pergunta-se "o quão longe estão um do outro?", e diagnose, quando o aprendiz perguntase "o que é necessário fazer para chegar até lá?".

\section{As Categorias de análise}

No caso dos nossos dados os desnivelamentos em questão advêm do reconhecimento de lacunas entre: (1) uma percepção da realidade escolar e uma afirmação do texto; ou (2) uma percepção da realidade escolar e uma inferência feita por um dos membros do grupo sobre o texto; ou ainda (3) uma percepção da realidade escolar e uma avaliação sobre determinada ação de dado professor, realizada por outro membro do grupo.

Nos episódios que descreveremos a seguir trataremos de quatro tipos de casos: quando a lacuna foi percebida pelo professor sem que houvesse visualização de uma ação possível; quando a lacuna foi percebida pelo professor e ele visualizou ações possíveis, porém, não factíveis; quando a lacuna foi percebida pelo professor e ele visualizou açōes imaginadas como factíveis; quando a percepção da lacuna acabou por disparar a realização de uma ação. Para cada um destes casos criamos uma categoria de análise diferente. No primeiro caso, chamamos o desnivelamento de imenso, no segundo, de grande, no terceiro, de desafiador, e no quarto, de ativo. 


\section{Desnivelamento imenso: diferentes percepçôes de uma mesma lacuna}

Logo no início das atividades do grupo, durante um seminário realizado por P3 sobre o artigo estudado, o grupo manifestou concordância sobre certa idéia extraída do texto, segundo a qual o professor pode oferecer ao aluno um feedback de melhor qualidade do que aquele implicado na mera atribuição de notas ${ }^{3}$, P2 fez uma pergunta: é verdade que este ano vamos trabalhar, aqui na escola, com escala de notas de zero a dez? A nosso ver, P2 estava propondo a comparação entre o método de avaliação adotado pela escola e a afirmação do texto. Sem prestar muita atenção P3 respondeu afirmativamente retomando em seguida a leitura do texto. P3 admitiu depois que não considerava genuíno o engajamento de P2 no grupo e assim não investia esforços significativos na sua interação com ele. Porém, P2 insistiu na sua provocação, perguntando se aquela era uma determinação da escola ou se havia alguma lei que regulasse o assunto.

No questionamento de P2 estava implícita uma enorme lacuna: entre uma afirmação do texto, sobre a exigência de qualidade no feedback fornecido pelo professor, e uma percepção do grupo sobre a realidade escolar na qual estava inserido, referente à avaliação praticada na escola. Entendemos que a insistência dele em retomar o assunto denuncia uma atitude deliberada de jogar para o grupo uma impossibilidade, como se ele quisesse desafiar crenças dos professores sobre a viabilidade de um trabalho colaborativo em prol da melhoria da escola.

Na verdade, o que conferiu relevância ao episódio foi o fato de a provocação de P2 ter suscitado discussão generalizada. De alguma forma todos reagiram diante da lacuna introduzida por P2. Em outras palavras: o grupo sentiu-se atingido pela provocação contida nas perguntas de P2. P1 relatou como ocorreu a decisão de alterar o regimento escolar, relativamente ao método de avaliação adotado pela escola, durante uma reunião dos professores: dos cinqüenta e oito professores da escola, estavam presentes na reuniāo, trinta e cinco e, quando a diretora colocou o sistema de notas ou conceitos em votação, trinta e dois professores optaram pela nota de zero a dez, apenas eu votei contra e dois se abstiveram de votar. Sentindo-se cobrados, os professores passaram a reavaliar suas posições sobre o tema. P5 e P2 lembraram prontamente que não estavam presentes naquele dia. Enquanto P5 defendia a sistemática de notas, P2 reclamava que isso não resolve nada e que estava usando conceitos na sua avaliação desde que se tornou professor. A discussão pareceu não interessar muito a $\mathrm{P} 3$, que a finalizou dizendo: eu acho que tanto faz você trabalhar com conceitos ou com notas, depende apenas de como você vai trabalhar. P4 reforçou sua posição relembrando uma fala sua anterior dizendo que: isso tem que ser trabalhado desde o começo; tem que haver uma mudança na própria cabeça do professor, começar desde cedo dizendo que a nota não é importante.

Podemos, neste episódio, falar em um desnivelamento diferente para cada membro do grupo, porém, em todos os cinco casos, caracterizamos os desnivelamentos como imensos, em vista do compartilhamento da percepção da impossibilidade de enfrentamento da lacuna detectada. No caso de P3, falaremos de desnivelamento imenso diligente, pois ela parecia estar mais preocupada em examinar o caminho que se está percorrendo, em ser processual. Para "não cair" na "armadilha" colocada por P2, a solução dada por ela foi a de avaliar o obstáculo, julgá-lo intransponível e, por fim, contorná-lo. Sabia que não estava preparada para enfrentar a imensidão daquela lacuna, no momento, e, portanto, resolveu desviar seus esforços para alvos mais

\footnotetext{
${ }^{3} \mathrm{O}$ segundo assunto (relacionado às dificuldades com a avaliação) é o impacto negativo: dar notas e classificar são atividades supervalorizadas, enquanto dar conselhos uiteis e a função da aprendizagem são subvalorizados. [...] O feedback para qualquer aluno deveria ser sobre as qualidades particulares do seu trabalho, com aconselhamento sobre o que ele pode fazer para melhorar e, as comparaçôes com outros alunos deveriam ser evitadas (Paul Black e Dylan Wiliam, 1998b, p. 5-6).
} 
producentes. De fato, P3 era a única do grupo que parecia envolver-se no trabalho de redimensionar metas, tornando-as menores e, assim, factíveis, o que será percebido também em outros episódios. Esta atitude pode ser relacionada a uma análise feita por Villani e Orquiza de Carvalho (1995), que, na investigação sobre os conflitos cognitivos de estudantes, encontraram a suspensão ou abandono parcial do conflito.

No caso de $\mathrm{P} 5$, que se pronunciou favoravelmente à utilização de notas, falaremos de desnivelamento imenso recalcado, o que significa que P5 preferiu não reconhecer a lacuna. No caso de P1 e P4, falaremos em desnivelamento imenso contemplativo, pois perceberam a lacuna, mas permaneceram na consideração teórica, sem propor nenhuma ação de fechamento. No caso de P2, falaremos de desnivelamento imenso desmobilizador, pois entendemos que essa lacuna não implicava que ele estivesse colocando uma meta pessoal ou para o grupo, mas uma impossibilidade.

Acreditamos que a lacuna exposta (entre o método de avaliação adotado pela escola e o padrão de referência levantado pelo texto) remeteu os esforços de pensamento do grupo à impossibilidade de modificar o "sistema de ensino", o que também sugere o grau de dificuldade que os professores enfrentam diante da proposta de discutir avaliação formativa na escola. A avaliação formativa implica a crença de que pequenas mudanças podem e devem ser, incansavelmente, implementadas na prática de ensino. Como conciliar essa crença com a percepção de que há todo um "sistema de ensino" por ser mudado? A dificuldade permanece em se conseguir conciliar as análises macro e micro da situação de ensino e mais ainda, em compartilhar visōes com outros professores.

Vale ainda ressaltar que um desnivelamento muito grande pode ser experimentado, pelo sujeito, como um conflito cognitivo (Villani e Orquiza de Carvalho, 1995), o que significa que, apesar do reconhecimento da lacuna, uma meta ainda não foi estabelecida pelo aprendiz, pois ele ainda está questionando se o feedback recebido vai adquirir o status de padrão de referência a ser perseguido. Assim, no conflito, o aprendiz percebe a lacuna, mas não fixa o seu padrão de referência. Enquanto isso não acontece, acreditamos que qualquer ação possível fica impossibilitada. De fato, isto nos remete a Sadler (1989, apud Black \& Wiliam, 1998a) que afirma que "quando o indivíduo percebe a lacuna revelada pelo feedback como muito extensa, a sua ação para fechá-la será inibida” (p. 54).

\section{Desnivelamento grande e desnivelamento desafiador diante da mesma lacuna}

Uma nova lacuna pode ser detectada no sexto encontro, quando P5 apresentou certa angústia diante do esforço de "promover a auto-avaliação do aluno". Apesar de admitir mudanças na sua forma de pensar (existe uma outra maneira de avaliar para se chegar a resultados melhores), devido às leituras que realizou, P5 imaginava que as dificuldades eram grandes demais: porque a cabeça do aluno ainda está naquela de classificação (...) auto-avaliação é difícil de você realizar. No geral, eu achei que estamos caminhando para isso. Não totalmente. Na maioria das classes, na maioria das aulas, eu me vejo fazendo isto. Nas demais classes, eu falei assim: eu não vou agüentar, a classe está fervendo. Não tem condição. Na seqüência da fala de P5, P1 manifestou-se, concordando com a necessidade de mudanças na prática sobre avaliação e reconhecendo, com certa tranquiilidade, as dificuldades a serem enfrentadas para implementar a auto-avaliação. No entanto, defendeu a necessidade de paciência, pois a prática sofre uma mudança mais lenta; no que foi apoiada por $\mathrm{P} 3$.

Também neste episódio constatamos diferentes desnivelamentos para uma mesma lacuna: entre o padrão de referência implícito na necessidade reconhecida de promover a autoavaliação do aluno e a percepção de que os alunos estão imersos no paradigma classificatório. 
No caso de P5, chamamos o desnivelamento de grande, pois diferentemente do caso dos desnivelamentos imensos, o professor demonstrou que tinha estabelecido uma meta, que consistia em dar atendimento individual ao aluno (fui chamando o aluno, perguntando), mas desistiu dela, no meio do caminho, por perceber que era maior do que esperava (eu não vou agüentar). Nos casos de P1 e P3, falaremos de desnivelamento desafiador, pois apesar do reconhecimento da dificuldade implicada na meta, esta era considerada como factível.

\section{Desnivelamento ativo de transbordamento}

Dentre os desnivelamentos ativos percebidos, exemplificaremos com um que denominamos de desnivelamento ativo de transbordamento, que ocorreu quando o grupo estava lendo um trecho* do texto em que os autores discutem como aperfeiçoar a avaliação formativa através de investimento na melhoria da auto-estima dos alunos. P3 relatou que, ao voltar de uma licença-prêmio, encontrou seus alunos aflitos por não saberem a nota do último bimestre. A professora substituta explicou-lhe que não entregara as notas finais para os alunos porque, se o tivesse feito, os alunos não teriam vindo mais para a escola. P3 mostrou-se muito indignada com a atitude da professora, pois esta usara a nota como um recurso para segurar o aluno na escola. Em sua indignação, referiu-se à pobreza na qualidade do "feedback" dado pela professora.

A lacuna percebida por P3 localizava-se entre a prática da professora substituta e as idéias que a própria $\mathrm{P} 3$ passara a valorizar. De fato, como ela própria admitiu, o trecho do texto somente foi valorizado quando ela o relacionou com episódio que envolvia a outra professora. Ao chamar a atenção do grupo para o fato, relacionando-o ao texto, compreendeu que recontextualizara seu entendimento sobre a importância do feedback: a avaliação tem que ser usada para mostrar para o aluno o que ele aprendeu e o que ele não aprendeu... O aluno deve ser informado se ele foi bem, se ele foi mal, o que ele acertou, o que ele errou, o que ele aprendeu, o que não aprendeu.

Interessante evidenciar o duplo efeito de valorização ocorrido neste caso. Inicialmente, a valorização do texto possibilitou a interpretação e a valorização negativa da atitude da professora substituta. Posteriormente, a percepção da lacuna trouxe valorização para a teoria que estava sendo estudada e, além disso, influenciou a autoconfiança de P3 em sua interação com o grupo de estudo.

Consideramos que este desnivelamento foi do tipo ativo de transbordamento porque a percepção da lacuna, por P3, disparou a ação de compartilhar com os outros professores uma descoberta. Através desse compartilhamento, ela própria pode pensar e organizar suas novas idéias. A palavra transbordamento quer indicar que a preocupação de P3, neste momento, não era a de mediadora das descobertas dos outros professores, papel a que tinha se proposto desde o começo, mas de exposição e reflexão de suas próprias.

\section{Conclusão}

Neste trabalho, expusemos um grupo de professores de Ciências à reflexão sobre a implementação da avaliação formativa. Ao analisar os resultados de pesquisa percebemos que três diferentes níveis de realização da auto-avaliação ocorreram simultaneamente, alimentando-se mutuamente: a auto-avaliação dos alunos, geradora de todos os processos envolvidos nesta pesquisa; a auto-avaliação dos professores, que se colocaram na posição de refletir sobre

\footnotetext{
* O principal usuário da informação sobre a avaliação que visa o aperfeiçoamento da aprendizagem é o aluno. Existem aspectos negativos e positivos deste fato. O aspecto negativo é ilustrado pela citação de Perrenoud, (1991): "todo professor que deseja praticar a avaliação formativa precisa reconstruir seus contratos de ensino de modo a neutralizar os hábitos adquiridos por seus alunos" (Paul Black e Dylan Wiliam, 1998b, p. 6).
} 
a avaliação formativa; e a auto-avaliação das pesquisadoras, que para investigar colocaram-se na posição de formadoras de professores. Parece-nos que, em qualquer um dos três níveis, vale o seguinte: a auto-avaliação ocorre quando um agente lança-se em uma ação que crê ser viável, projetando-se em direção ao grupo social e assim provoca a instauração de um processo de comparação entre o estado presente e um padrão de referência por ele identificado e valorizado. Este processo resulta na produção de conhecimento e no ganho de novos elementos para reflexão futura, com repercussões para uma maior autonomia do agente. Segundo Lash (1997), "se somos arremessados nos significados e práticas coletivas do estar-no-mundo de uma comunidade", somente arremessamo-nos nesse mundo na medida em que decidimos participar com outros em sua criação.

O foco principal de nossa análise deteve-se na auto-avaliação dos professores. A partir de um paralelo entre auto-avaliação do aluno e auto-avaliação do professor, identificamos maneiras de o professor se relacionar com um padrão de referência por ele identificado em um texto estudado ou em inferências feitas pelos outros professores que participavam do estudo. Concluímos que, quando um padrão de referência acaba por se impor ao professor, através do seu contato com o conhecimento historicamente construído, mais especificamente, com a teoria dos especialistas, ainda lhe cabe resolver a questão de como reagir diante dele.

Somente indícios de mobilização garantem que o padrão de referência ganhou, efetivamente, status de meta a ser perseguida. Isto certamente não ocorreu na primeira categoria por nós identificada, que chamamos de desnivelamento imenso, quando, então, as comparaçóes entre o estado presente e o referente teórico permanecem apenas como igualdade e distância (Kluger \& DiNisi, 1996). A terceira e a quarta categorias caracterizam-se justamente pela definição de uma meta factível, que pode ser atualizada ou não. No caso de atualização, falamos em desnivelamento ativo (quarta categoria) e, no caso de não atualização, falamos em desnivelamento desafiador (terceira categoria). A segunda maneira, correspondente ao desnivelamento grande, é intermediária entre a primeira e a terceira, quando, então, o professor oscila entre estabelecer uma meta e desistir dela, o que implicaria voltar a considerar o desnivelamento em termos de igualdade ou distância.

A auto-avaliação das pesquisadoras referiu-se ao desnivelamento percebido por elas entre diferentes traduçôes possíveis, do termo inglês gap, que pareciam ser, no princípio, de difícil conciliação. Aplicando nossas categorias de análise também para este caso, consideramos que o desnivelamento das pesquisadoras iniciou-se como grande e foi fechado quando redefinimos o significado de lacuna e de modo a eliminar certa ambigüidade nele contida, estabelecemos as categorias de análise.

O ponto crucial nesta questão está no fato de que somente após o reconhecimento da lacuna, o aprendiz pode avaliar sua amplitude, o que poderá levá-lo a se posicionar diante dela e até mesmo a tomar consciência de que diminuí-la exige comprometimento de sua parte. De fato, somente na melhor das hipóteses o reconhecimento de um padrão de referência implica clareza na definição de uma meta e conseqüente mobilização do aprendiz, pois mesmo depois de ter valorizado um referente teórico, ele terá que decidir se a ação implicada será realizada, adiada, ou se a lacuna será recontextualizada, de modo a se tornar menor e factível. Portanto, entendemos que a palavra meta poderá ser utilizada somente no terceiro dos casos de Kluger e DiNisi (1996), quando o aprendiz pergunta-se “o que é necessário fazer para chegar lá?", não bastando, para seu estabelecimento, a percepção de uma lacuna.

Ao processo que se inicia com o reconhecimento de uma lacuna e pode finalizar com a mobilização pessoal em busca da realização de uma meta, chamamos de auto-avaliação ou mais especificamente no caso do professor, autoformação. 
Por último, consideramos que nosso ponto de partida - proposta de estudo em grupo de um texto sobre avaliação formativa acompanhada da perspectiva de implementação da própria avaliação formativa - introduziu, na discussão com os professores, já de início, a teoria dos especialistas, através de um referencial teórico (aquele implícito nos textos estudados) que era estranho para a maior parte dos integrantes do grupo. Estava implícita, nesta postura, a idéia de que o professor produz teorias pedagógicas próprias, na sua prática cotidiana (Zeichner, 1993; Carr e Kemmis, 1988), e que estas necessitam ser validadas.

Nesse sentido, parece-nos que o tema escolhido para a discussão no grupo de professores, a avaliação formativa, constituiu um elemento potencializador da tensão entre as análises macro e micro que o professor elabora sobre o mundo escolar, o que favoreceu o processo de produção das teorias próprias dos professores, no ambiente do grupo.

Assim, sugerimos que sejam oferecidas aos professores de Ciências oportunidades de longo prazo para vivenciar uma dupla situação: por um lado, examinar as concepções e visões compartilhadas com outros professores sobre a possibilidade/impossibilidade de modificar o sistema educacional, sobre viabilidade/inviabilidade do trabalho colaborativo no cotidiano escolar, sobre a relação entre teoria e prática, sobre a validade das teorias pedagógicas dos especialistas etc. e, por outro, implementar possíveis ações pessoais projetadas no futuro imediato, a serem realizadas no seu círculo mais direto de interrelações do professor, principalmente aquele contextualizado em sua sala de aula.

\section{Referências}

ABRECHT, R. A avaliação formativa. Trad. José Carlos Tunas Eufrásio. Rio Tinto: Edições ASA, 1994. (Coleção: práticas pedagógicas).

BLACK, P.; WILIAM, D. Assessment and classroom learning. Assessment in Education, v. 5, n. 1, p. 7-73, 1998a.

. Inside the black box: raising standard through classroom assessment. Phi Delta Kappan, Bloomington, p. 139-148, out. 1998b.

CARR, W.; Kemmis, S. Teoria crítica de la ensenãnza: la investigación-acción en la formación del professorado. Barcelona: Martinez Roca, 1988.

FIORENTINI, D. Saberes docentes: um desafio para acadêmicos e práticos. In: GERALDI, F. e P. (Org.). Cartografias do Trabalho Docente. Campinas: Mercado das Letras, 2001.

Kluger, A. N.; DiNisi, A. The effects of feedback intervention on performance: a historical review, a meta-analysis, and a preliminary feedback intervention theory. Psychological Bulletin, Washington, v. 119 , p. $254-284,1996$

LASH, S. A Reflexividade e seus duplos: estrutura, estética, comunidade. In: Giddens, A.; BECK, V.; LASH, S. (Org.). Modernização reflexiva: política, tradição e estética na ordem social moderna. Tradução de Magda Lopes. São Paulo: Unesp, 1997. p. 135-206. 
MARTINEZ, C. L. P. Explorando o potencial da avaliação formativa: análise de uma experiência centrada na escola. 2001. 123 f. Dissertação (Mestrado) - Faculdade de Ciências, Universidade Estadual Paulista, Bauru, 2001.

MATURANA, H.; VARELA, F. A árvore do conhecimento. São Paulo: Palas Athena, 2001.

ORTON, R. E. Toward an Aristotelian model of teacher reasoning. Journal of Curriculum Studies, Basingstoke, v. 29, n. 5, p. 569-583, 1997.

PERRENOUD, P. Avaliação: da excelência à regulação das aprendizagens - entre duas lógicas. Trad. Patrícia Chittoni Ramos. Porto Alegre: Artes Médicas Sul, 1999. 183 p.

PIAGET, J. O possível e o necessário. Trad: Manuel Campos. São Paulo: Martins Fontes, 1993. v. 1.

SAWYER, R. Teachers who grow as collaborative leaders: the rocky road of support. Education Policy Analysis Archives, v. 9, n. 38, 2001.

SHULMAN, L.S. Knowledge and teaching: foundations of the new reform. Harvard Educational Review, Cambridge, v. 57, n. 1, p. 1-22, 1987.

TARDIF, M. Saberes profissionais dos professores e conhecimentos universitários. Revista Brasileira de Educação, Belo Horizonte, n. 13, jan./abr. 2000.

VILLANI, A; ORQUIZA DE CARVALHO, L. Conflitos cognitivos, experimentos cualitativos y actividades didacticas. Enseñanza de las Ciencias, Barcelona, v. 13, n. 5, p. 279-294, 1995.

VILLANI, A. O professor de ciências é como um analista? Ensaio: Pesquisa em Educação em Ciências, Belo Horizonte, v. 1, n. 1, p. 5-28, 1999.

ZEICHNER, K. M. A formação reflexiva dos professores: idéias e práticas. Lisboa: Educa, 1993. 